\title{
Prevalence of Non-Communicable Diseases and Social Interactions in Kenya: An Empirical Analysis
}

\author{
Daniel Mwai M.A, PhD, \\ The Palladium Group, Nairobi, Kenya
}

doi: 10.19044/esj.2016.v12n8p170 URL:http://dx.doi.org/10.19044/esj.2016.v12n8p170

\begin{abstract}
Despite a remarkable progress in the control and management of communicable diseases over the past century, the world is not better-off as the prevalence of Non-Communicable Diseases (NCD) is on the increase, both in developed and developing countries. The upsurge in NCD prevalence is attributable to risk factors both outside and within the control of individuals. One risk factor that has received less attention than it deserves is the social interactions variable. Social interactions are the established relationships among individuals, e.g., among peers or persons in the same circumstances. Interactions of persons in the same circumstances affect behavior because of the necessity for the individual to conform to established group norms or values. It is believed that NCD prevalence in Kenya is high in sections of the populations where social interactions among certain groups is intense, but little evidence exists in support of this supposition. This paper examines this assumption taking into account the endogeneity of behavior in a group setting .In particular, we estimate a binary probit model of an individual contracting a non-communicable disease, conditional on engaging in certain consumption behaviors that are malleable by peer or group pressure. The key finding from the estimation exercise is that variables that capture social interactions such as the village level means of drinking alcohol, consuming vegetables and fruits, and smoking cigarettes are significantly associated with the likelihood of getting an NCD. The policy implication of this finding is that NCD prevalence in Kenya can be reduced by implementing programs to change health behaviors within social groups.
\end{abstract}

Keywords: Social interactions, Non-communicable Disease, Risk factors, Endogeneity 


\section{Introduction}

Though there has been a remarkable progress in the control and management of communicable diseases in $20^{\text {th }}$ century as observed by WHO (2002a) and Tawa et al, (2011), Non-Communicable Diseases have taken an upward trend thus imposing healthcare burdens on both developed and developing economies. It is in this light that Nguyen et al, (2011) and Maina, (2009) have argued that in the 21st century NCDs will pose a major challenge in health programming. NCD prevalence has been widely linked to the exposure of identifiable risk factors that are fuelled by behaviors that are influenced by group norms, values or sanctions. WHO (2002b) and Boutayeb (2006) note that low intake of fruits and vegetables, cigarette smoking and excessive consumption of alcohol together account for close to 95 per cent of NCDs prevalence worldwide. Boutayeb and Boutayeb (2005) argue that NCD risk factors are country specific and vary in form and presentation and hence the need for county specific responses to them.

As much as Unwin (2006), Yusuf et al, (2004) and Gupta et al, (2006) have shown that major NCDs operate through a cluster of common risk factors that are sometimes outside the control of an individual or household, Rosenzweig and Schultz (1983) have argued that a household's exposure to NCD risk factors could be largely influenced by decisions taken by others in a social network. Social networks are made up of individuals or households with strong ties and likelihood of exchanging information with each other. The social networks typically comprise relatives, friends and neighbours (Rosenzweig and Schultz, 1983). Becker (1974) underlined the importance of analysing individual behaviours with reference to the behaviour and characteristics of a group... Although social interactions are considered in sociological and anthropological studies and economic literature of early nineteenth century, they are largely ignored in modern economic analysis. Becker (1974) concludes that failure to account for social interactions when, say, estimating health production or consumption functions leads to biased results.

According to Hartmann et al, (2008) social interactions occur whenever an individual or a household in a group or neighbourhood affects other households' choices directly without the intermediation of the market. This manifests social effects on the members of the group or neighbourhood. As noted, NCDs risk factors are acquired or enhanced in a group context. Caudill and Kong (2001), Larsen et al. (2009) and Quigley and Collins (1999), show that individuals increase alcohol consumption when they keep company of heavy drinkers. Engels and Knibbe (2000) highlight that alcohol and tobacco smoking give social identity, and a sense of belonging to and connecting to friends and peers. Sun and Green (2003) concur and argue that alcohol consumption and smoking are social in 
nature, and people generally consider other people's drinking patterns and behaviours in determining their own consumption levels. Many are the times when individuals impulsively mimic the behavior of role models without recognizing that they are so doing (Van Baaren, 2003, Harakeh et al, 2007)). This is a form of social interaction mediated through observation.

Eating food together plays a social role in people's lives. The quantity of food consumed is related to the social environment within which it is eaten (Hermans et al, 2009). If this social influence is not controlled for in modelling human behaviour, the estimated parameters become biased. Dijksterhuis (2005) observes that failure to take into account social interactions is to ignore the social glue that makes people social animals. Bandura (1977, 1986) argues that social interactions play a role in the development and maintenance of lifestyle behaviours that have a large effect on individual and household health production.

Social interactions have been shown to be important in individual and household decision-making as they influence choices. Adam Smith ${ }^{52}$ recognized the role of social interaction in economic behaviour but may have been wrong in down-playing their role arguing that the greater part of men is not frequently under the influence of such interactions (Smith, 1937). However, Veblen argued that "social interactions are the very stuff of life that dominates everything else” (Veblen, 1934). Therefore, in understanding the risk and mitigating factors in the spread of NCDs there is need to assess the role of social interactions.

NCD in Kenya has taken a very new dimension where slum and rural areas have registered an increasing manifestation of diabetes which is currently the major NCD in Kenya (Ayah et.al, 2013 and Hemed et.al, 2014). The two areas are known to have intensive social interactions.

The purpose of this paper is to evaluate the influence of social interactions on NCDs prevalence in Kenya.

\section{METHODOLOGY AND DATA}

The study utilizes a health production function to estimate the effect of the identified risk factors on the probability of an individual getting an NCD. The paper evaluates the effects of social interactions on NCD occurrence following Becker (1974) and Bandura (1977, 1986). Social interactions are hypothesized to take place in social networks based on proximity of individuals within a network (Balsa et al, 2014, 2010; Bandiera and Rasul, 2006). A person is assumed to take action on the basis of dominant opinions and behaviours of neighbors or peers (DeGiorgi, Pellizzari and Redaelli, 2009; Eisenkopf, 2010). Thus we include

\footnotetext{
${ }^{52}$ Adam smith referred to social interactions as "passions”
} 
neighborhood variables in an NCD function. . The coefficients of these variables show the effect of average exposure to community level behavioural variables on an individual's health status, measured here by the presence of an NCD. Following Wooldridge (1997), Niringiye (2010) and Greene (2012) the models we estimate are as specified in equations (1) and (2).

$$
\begin{aligned}
& n c d=c_{0}+c_{1} Z_{i}^{\prime}+\beta_{i} X_{i}^{\prime}+\alpha_{i} \bar{W}_{i s}+\varepsilon_{i} \\
& Z_{i}=\lambda K_{j}^{\prime}+\beta_{j} X_{i}^{\prime}+\alpha_{j} \bar{W}_{i s}+\varepsilon_{j}
\end{aligned}
$$

Where ncd is non-communicable diseases, $Z_{i}$ is a vector of endogenous variables, and $X_{i}^{\prime}$ is a vector of exogenous variables. $K_{i}^{\prime}$ is a vector of exogenous variables that are instruments for $Z_{i} \cdot \bar{W}_{i s}$ is a vector of social interaction variables in villages. Since social interactions are not observable they are proxied by the means of alcohol consumption, cigarette smoking, vegetables and fruits consumption, all measured at the district level ${ }^{53}$. Household i's observation in each respect is excluded in calculation of its pertinent mean. By excluding the observation of the household in question from village means, the influence of the village mean is insulated from the action of an individual or household. The coefficients $c_{0} c_{1} \quad \begin{array}{ll}\beta & \alpha\end{array}$ and $\lambda$ are the parameters to be estimated, while $\varepsilon_{i}$ and $\varepsilon_{j}$ are the disturbance terms.

Equation (1) has multiple endogenous regressors which include alcohol consumption, smoking and vegetable intake.. Equation (2) specifies reduced form equations for all the endogenous variables in vector $Z_{i}^{\prime}$ in equation (1). The validity of the instruments has been assessed in line with Nelson and Startz (1990) and Staiger and Stock (1997). Several diagnostics tests based on the F-test for joint significance of coefficients on potential instruments were conducted (see (Ajakaiye and Mwabu 2007 and Mwabu 2009).

This study uses data from the 2007 Kenya Household Expenditure and Utilization Survey (KHHEUS), a national survey conducted by the Kenya National Bureau of Statistics (KNBS) on behave of the Ministry of health. This survey collected information on a wide spectrum of socioeconomic indicators designed to monitor, analyse and measure the progress made in improving living standards in Kenya. The sample consisted of 8,844 households, 6072 of them rural and 2772 urban. Of these 8,453 were

\footnotetext{
${ }^{53}$ The district was used as a proxy for village/ neighborhood. Districts have become counties in the new constitutional dispensation.
} 
successfully interviewed giving a response rate of 96 per cent. The survey reported observations on 39,798 individuals who belonged to 8,423 households out of 8,844 households sampled. The survey covered all provinces in Kenya, with a total of 737 clusters selected and divided into 506 (68.7 per cent) rural and 231 (31.3 per cent) urban. Neighbourhood variables were generated as mean values in a village or district.

\section{Results and discussion Descriptive statistics}

The respondents in the survey had a mean age of 30 years, and 52 per cent of the respondents were females. About 32 per cent of respondents reported consuming some quantity of vegetables and fruits; 12 per cent reported consuming alcohol (beer, wine and traditional brews), and 8 per cent were smokers. About 62 per cent were not married while 79 per cent lived in rural areas. On the other hand about 69.7 per cent reported having attained primary-school education, and only 1.3 per cent had acquired university education. On average household members travelled a distance of 1.44 kilometres to access health services from the nearest health facility.

\section{Regression analysis}

Table 2 presents results from estimation of equation (1). We interpret control function results presented in column (3).

Table 1: NCD risk factors in Kenya (Dependent variable is NCD dummy)

\begin{tabular}{|c|c|c|c|}
\hline & \multicolumn{3}{|c|}{ Estimation method } \\
\hline Explanatory Variable & $\begin{array}{l}\text { Probit } \\
\text { (1) }\end{array}$ & $\begin{array}{c}\text { Control function } \\
\text { estimates }\end{array}$ & $\begin{array}{c}\text { Control } \\
\text { function } \\
\text { estimates } \\
\text { controlling } \\
\text { for } \\
\text { heterogenei } \\
\text { ty (3) } \\
\end{array}$ \\
\hline Age & $\begin{array}{c}0.0265^{* *} \\
{[0.0016]}\end{array}$ & $\begin{array}{l}0.0058^{*} \\
{[0.0120]}\end{array}$ & $\begin{array}{l}0.0053 * \\
{[0.0064]}\end{array}$ \\
\hline Age squared & $\begin{array}{l}-0.0102 * \\
{[0.0142]}\end{array}$ & $\begin{array}{l}0.0141 * * \\
{[0.0120)}\end{array}$ & $\begin{array}{c}0.0243 * * * \\
{[0.0112]}\end{array}$ \\
\hline Urban & $\begin{array}{c}0.0387 * * \\
{[0.0034]}\end{array}$ & $\begin{array}{l}0.0915^{* *} \\
{[0.0404]}\end{array}$ & $\begin{array}{l}0.0542 * * \\
{[0.0269]}\end{array}$ \\
\hline Female & $\begin{array}{c}0.0162 * * \\
{[0.0026]}\end{array}$ & $\begin{array}{l}0.1099 * * \\
{[0.0446]}\end{array}$ & $\begin{array}{l}0.0741 * * \\
{[0.0373]}\end{array}$ \\
\hline Log household income & $\begin{array}{c}0.0039 * \\
{[0.0014]} \\
\end{array}$ & $\begin{array}{c}0.0824 * * * \\
{[0.0197]} \\
\end{array}$ & $\begin{array}{c}0.0420 * * * \\
{[0.0120]}\end{array}$ \\
\hline Years of schooling & $\begin{array}{l}0.0100^{*} \\
(0.034)\end{array}$ & $\begin{array}{l}-0.0100^{*} \\
(0.0027)\end{array}$ & $\begin{array}{l}-0.0101^{*} \\
(0.0283) \\
\end{array}$ \\
\hline Alcohol dummy (1=excess alcohol) & $\begin{array}{c}0.0166 \\
{[0.0185]}\end{array}$ & $\begin{array}{c}-0.0583 * * \\
{[0.0924]}\end{array}$ & $\begin{array}{l}0.2038 * * \\
{[0.0243]}\end{array}$ \\
\hline Cigarette dummy (1=smokes) & $\begin{array}{c}0.0043 \\
{[0.0052]}\end{array}$ & $\begin{array}{c}0.3674 * * * \\
{[0.2095]}\end{array}$ & $\begin{array}{c}0.5139 * * * \\
{[0.3210]}\end{array}$ \\
\hline Fruits/vegetable dummy (1=adequate & 0.0039 & $-0.6210 * * *$ & $-0.6677 * * *$ \\
\hline
\end{tabular}




\begin{tabular}{|c|c|c|c|}
\hline & \multicolumn{3}{|c|}{ Estimation method } \\
\hline Explanatory Variable & $\begin{array}{c}\text { Probit } \\
(1)\end{array}$ & $\begin{array}{c}\text { Control function } \\
\text { estimates }\end{array}$ & $\begin{array}{c}\text { Control } \\
\text { function } \\
\text { estimates } \\
\text { controlling } \\
\text { for } \\
\text { heterogenei } \\
\text { ty (3) } \\
\end{array}$ \\
\hline intake) & [0.0029] & {$[0.0681]$} & [0.0646] \\
\hline Mean district alcohol consumption & $\begin{array}{c}-0.0017 \\
{[0.0015]}\end{array}$ & $\begin{array}{l}0.0195 * * \\
{[0.0138]}\end{array}$ & $\begin{array}{c}0.0849 * * \\
{[0.0076]}\end{array}$ \\
\hline Mean district cigarette consumption & $\begin{array}{c}-0.0019 \\
{[0.0018]}\end{array}$ & $\begin{array}{c}-0.0418 * * \\
{[0.0148]}\end{array}$ & $\begin{array}{l}0.0303 * * \\
{[0.0096]}\end{array}$ \\
\hline $\begin{array}{l}\text { Mean district fruits and vegetables } \\
\text { consumption }\end{array}$ & $\begin{array}{l}0.0132^{* *} \\
{[0.0019]} \\
\end{array}$ & $\begin{array}{l}0.1205^{* *} \\
{[0.0281]} \\
\end{array}$ & $\begin{array}{c}-0.0640 * * \\
{[0.0183]}\end{array}$ \\
\hline Distance to health facility & $\begin{array}{c}0.0502 * * \\
* \\
{[0.0170]} \\
\end{array}$ & $\begin{array}{l}0.1737 * * \\
{[0.0885]}\end{array}$ & $\begin{array}{l}0.0775 * * \\
{[0.0328]} \\
\end{array}$ \\
\hline Alcohol residual & & $\begin{array}{c}-0.0670 * * \\
{[0.2127]}\end{array}$ & $\begin{array}{c}-0.0766^{* *} \\
{[0.4525]}\end{array}$ \\
\hline Cigarette residual & & $\begin{array}{c}-0.2222 * * * \\
{[0.0913]} \\
\end{array}$ & $\begin{array}{c}-0.1344 * * * \\
{[0.0543]}\end{array}$ \\
\hline Fruits and vegetables residual & & $\begin{array}{c}0.4714 * * * \\
{[0.1181]} \\
\end{array}$ & $\begin{array}{l}0.1363 * * \\
{[0.0640]}\end{array}$ \\
\hline Cigarette* residual & & & $\begin{array}{c}0.0229 \\
{[0.0233]}\end{array}$ \\
\hline Fruits/vegetables* residual & & & $\begin{array}{c}0.3764 * * * \\
{[0.0926]} \\
\end{array}$ \\
\hline Alcohol* residual & & & $\begin{array}{c}-0.0945^{* *} \\
{[0.0675]}\end{array}$ \\
\hline Sample size & 32721 & 32721 & 32721 \\
\hline
\end{tabular}

Source: Author's computation. Note: ${ }^{* * *}, * *$ and * represent significance at $1 \%, 5 \%$ and $10 \%$, respectively. Standard errors are in parenthesis.

The probit results reported in Table 1, column (1) have not controlled for endogeneity and heterogeneity problems. Although IV regression results presented in column (2) controls for endogeneit making the results more preferable than probit, they do not control for heterogeneity. This study interpolate the results from the control function approach (2SRI with extensions) which have controls for both endogeneity and heterogeneity making the results more preferable.

Table 1 column (3) shows that a percentage increase in the proportion of smokers and heavy drinkers in the population elevates the likelihood of getting an NCD by $0.514 \%$ and $0.204 \%$, respectively. The results are consistent with those reported by Shona et al, (2011) and Ahmed et al, (2009).

A percentage increase in the proportion of people consuming adequate quantities of vegetables and fruits reduces the likelihood of developing NCDs by 0.67 per cent. The results are consistent with those of WHO (2002b) that show that low fruit and vegetable intake accounts for 41 
per cent of NCDs, such as coronary heart disease and ischaemic stroke. WHO (2005) and Nguyen et al, (2011) estimate that a person can reduce the likelihood of developing an NCD by close to 71 per cent through increasing the intake of vegetables and fruits.

The estimates further show that prevalence of NCDs is associated with neighbourhood variables proxied by district mean of alcohol consumption, cigarette smoking, and vegetable and fruit intake. A one percent rise in the mean consumption of alcohol and cigarette smoking in a district raises the likelihood of an NCD incidence in a household residing in the district by 8.49 and 3.03 per cent, respectively. It is also notable that the village mean consumption of fruits and vegetables is significant in reducing the probability of catching an NCD by $-0.06 \%$. These results support the argument that peer effects, social learning and neighbourhood effects significantly affect the probability of living with an NCD. The results are consistent with those of Larsen et al, (2010), Caudill and Kong (2001), Suls and Green (2003) and Herman et al, (2003). These studies conclude that negative behaviours like alcohol and cigarette consumption are social activities, and people generally monitor other people's drinking or smoking patterns to form their own patterns, thus strengthening Chartrand and Bargh (1999) statement that individuals acquire “chameleon attributes" by mimicking behaviors that they observe from others.. These social effects have negative implications on an individual's and household's health since they are associated with the increase of the risk of developing an NCD.

The finding that a one percent rise in the mean consumption of fruits and vegetables intake in a district reduces the likelihood of NCD incidence in a household residing in the district by $6.40 \%$ provides support for the observation that positive effects of social interactions can improve health and nutrition. This confirms the findings by Herman et al, (2003) that food and eating play an important role in people's social lives particularly when household members eat with or in the presence of others. The social context within which food is eaten has implications for its nutritional effects.

The study further shows living in an urban setting is associated with a 5.42 per cent likelihood of developing an NCD. The finding is consistent with Tawa et al, (2011) who found that living in an urban setting is characterized by high risk factor - such as crowding that increases the likelihood of having an NCD. The reasoning is that urban lifestyle is associated with clusters of risk factors due to low levels of physical activity, higher incomes that promote risky behaviours such as smoking, and consumption of processed foods with high fat content.

The results further show being female, living in an urban, smoking and alcohol consumption, low consumption of vegetables and fruits, aging, few years of schooling, and poor access to health care services are 
associated with increases the likelihood of having an NCD. The results support those of Lima et al, (2013), Tawa et al, (2011), Nguyen et al, (2011) Ahamed et al, (2009), Minh et al, (2009) and Taylor (2007).

\section{Conclusion and policy recommendations}

The probability of getting an NCD is linked to social, behavioral and biological risk factors. Accurate identification of risk factors is important in formulating suitable interventions to combat the rising incidence of NCDs in the country. This study has evaluated the effect of social interactions on NCD incidence using survey data from Kenya. The evaluation indicates that social interactions have large effects on the likelihood of developing an NCDs. Negative peer effects in alcohol consumption or cigarette smoking have adverse effects on a household health status. Positive peer effects in fruits and vegetables intake have salutary effects on a household's health and nutrition.

This study shows that social interactions matter in health production. A clear policy implication from this study is that health advocacy groups that have access to peer groups and social networks should be publicly supported to promote programs that can change health behaviours of group members in desired ways. Flaor instance, since being female increases the likelihood of acquiring NCD, targeting women groups with interventions geared towards mitigating the negative impact of NCD provide a feasible policy option in reducing the burden of NCDs among women.

\section{References:}

Ahmed S, Hadi A, Razzaque A..., (2009) Clustering of chronic noncommunicable disease risk factors among selected Asian populations: levels and determinants. NCD supplement Global Health Action Supplement 1. Ajakaiye O. and G. Mwabu, (2007). The Demand for Reproductive Health Services: Frameworks of Analysis. Mimeo, AERC. Nairobi.

Ayah R. ,Mark D.,Rosemary W.Elijah K.,Otieno F.,Neru E., and Mutai K. (2013). A population-based survey of prevalence of diabetes and correlates in an urban slum community in Nairobi, Kenyahttp://www.biomedcentral.com/1471-2458/13/371

Balsa, I, French, T, and Regan, T. (2010), In Review. Relative Deprivation and Health Compromising Behaviors among Adolescents Journal of Human Resources.

Bandiera O. and Rasul I. (2006). Social networks and technology adoption in Northern Mozambique. Economic Journal, 116:869-902.

Bandura, A, 1977. Social Learning Theory. Prentice-Hall, Englewood Cliffs, New Jersey. 
Bandura, A, 1986. Social Foundations of Thought and Action. PrenticeHall, Englewood Cliffs, New Jersey

Becker, G. (1974). A theory of social interactions Journal of political economy, $82 \quad$ (6) Nov-dec.1063-1093 viewed at http://www.jstor.org/stable/1830662

Boutayeb A. and Boutayeb S. (2005). The burden of communicable and non-communicable disease in developing countries. Int J Equity Health, 4: 2.

Boutayeb A. (2006). The double burden of non-communicable disease in developing countries. Trans R Soc Trop Med Hyg , 100: 191 - 199

Caudill, D, and Kong, H. (2001). Social approval and facilitation in predicting modeling effects in alcohol consumption. Journal of Substance Abuse, 13, 425-441.

Chartrand, L, and Bargh, A. (1999). The chameleon effect: The perceptionbehaviour link and social interaction, Journal of Personality and Social Psychology, 76, 893-910.

DeGiorgi G, Pellizzari M. and Redaelli S. (2009). Be as careful of the company you keep as of the books you read: Peer effects in education and on the labor market. NBER Working Paper Series, Working Paper 14948.

Dijksterhuis, AP. 2005 "why we are social animals: the high road to imitation as social glue." In the perspectives on imitation, vol 2, imitation, humana development , and culture, ed.S.Hurley and N. Chater, $2007-20$. Cambridge, MA: MIT press

Eisenkopf G. (2010). Peer effects, motivation, and learning. Economics of Education Review, 29:364-374.

Engels, R. C. M. E., and Knibbe, R. A. (2000). Alcohol use and intimate relationships: When love comes to town. Addictive Behaviors, 25, 435-439. Greene W. 2012. Econometric Analysis. Prentice Hall. USA.

Gupta I, Kandamuthan S, and Upadhaya D (2006). Economic impact of cardiovascular diseases in India. New Delhi: Institute of Economic Growth University of Delhi

Harakeh Z, Rutger, Van Baan et al.,(2007) imitation of cigarette smoking: An experimental study on smoking in a naturalistic setting. Drug and alcohol dependence, 86, 199 - 206

Hartmann, W.R. et.al. (2008). "Modeling Social Interactions: Identification, Empirical Methods, and Policy Implications,” forthcoming at Marketing Letters.

Hemed E.,Mariam D. Ahmed K.,Changambi M. Nahida K., and Hafsa P. (2014). How serious is the impact of TypeII diabetes in Rural Kenya? The Open Diabetes Journal, 2014, 7, 1-4 
Herman, P, Roth, A, and Polivy, J. (2003). Effects of the presence of others on food intake: A normative interpretation. Psychological Bulletin, 129, 873-886

Hermans, R, Engels R, Larsen, J ..., et al (2009), Modeling of palatable food intake, the influence of quality of social interaction. Elsevier, 52 (2009) 801-804

Larsen H, Engels R, Souren P..., et al (2010) Peer influence in a microperspective: Imitation of alcoholic and non-alcoholic beverages. Addictive Behaviors, 35, 49-52

Larsen, H., Engels, R.C.M.E., Granic, I., \& Overbeek, G., (2009). An experimental study on imitation of alcohol consumption in same-sex dyads. Alcohol and Alcoholism, 44, 250-255.

Lima M, Kerr-Côrrea F and Rehm J (2013) Alcohol consumption pattern and Coronary Heart Disease risk in Metropolitan São Paulo: analyses of GENACIS Project. Revista Brasileira de Epidemiologia, vol.16 no.1

Maina.W. (2009). Control of non-communicable disease in Kenya, past present and future. Nairobi: Ministry of health Kenya.

Minh H, Huong, D, Giang Kand Byass P (2009) Economic aspects of chronic diseases in Vietnam. Accessed at http://www.globalhealthaction.net/index.php/gha/article/view/1965/4840 Mwabu G. (2009). The production of child health in Kenya: A structural model of birth weight. Journal of African Economies, 18(2):212-260

Nelson C and Startz R. (1990). The distribution of the instrumental variables estimator and its t-ratio when the instrument is a poor one. Journal of Business, 63, 125-140.

Nguyen D,Datar A, Lepine F...,(2011) Active Starvation Responses Mediate Antibiotic Tolerance in Biofilms and Nutrient-Limited Bacteria, Science, 334- 982

Niringiye A and Douglason G (2010). Environmental and Socio-economic Determinants of Malaria Prevalence in Uganda. Research Journal of Environmental and Earth Sciences, 2(4): 194-198.

Quigley, B. M., \& Collins, R. L. (1999). The modeling of alcohol consumption: A metaanalytic review. Journal of Studies on Alcohol, 60, 90-98.

Rosenzweig, R, and Schultz P (1983), Estimating a Household Production Function: Heterogeneity, the Demand for Health Inputs, and Their Effects on Birth Weight. Journal of Political Economy, 91(5): 723-746.

Shona, D, Juan, B, Adebamowo, C..., et al, (2011) Non-communicable diseases in sub-Saharan Africa: what we know now International Journal of Epidemiology, viewed at http://ije.oxfordjournals.org/content/early/2011/04/27/ije.dyr050.full Smith A (1937). The wealth of the nations. New York; Modern library 
Staiger D and Stock J. (1997). Instrumental variables regression with weak instruments. Econometrica, 65, 557-586.

Suls, J., and Green, P. (2003). Pluralistic ignorance and college student perceptions of gender-specific alcohol norms. Health Psychology, 22, 479-486.

Tawa N, Frantz J, and Waggie F (2011). Risk factors to chronic non communicable disease in Mombasa, Kenya: Epidemiological study using WHO step wise approach. African journal of health science, 19: $24-29$

Taylor B, Rehm J, Aburto J., et al (2007) Alcohol, gender, culture and harms in the Americas: PAHO Multicentric Study final report. Washington: Pan American Health Organization.

Unwin,N, Mugusi, F, Aspray, T...,et al, ( 1999).Tackling the emerging pandemic of non-communicable diseases in sub-Saharan Africa: The essential NCD health intervention project. Public Health, 113:141-6.

Van Baaren, B, (2003). Mimicry: A Social Perspective. Doctoral Dissertation, Radboud University Nijmegen. Ridderkerk, S.I.: Ridderprint. WHO, (2002a). Non-communicable Diseases in the Southeast Asia Region: A Profile. New Delhi: Southeast Asia Regional Office.

WHO, (2002b). The world health report 2002- Reducing risks, promoting healthy life. Geneva, Switzerland.

WHO, (2005). Preventing Chronic Diseases: A Vital Investment. Geneva, Switzerland.

Wooldridge J. (1997). On two stage least squares estimation of the average treatment effect in a random coefficient model. Economics Letters, 56: 129-133

Yusuf S, Hawken S, Ounpuu S, Dans T..., et al , (2004) Effect of potentially modifiable risk factors associated with myocardial infarction in 52 countries (the INTER HEART study): case-control study. The Lancet, 364(1): 937-52. 